NASA Technical Memorandum 84562

GEOMETRICALLY NONLINEAR ANALYSIS OF ADHESIVELY BONDED JOINTS

B. Dattaguru, R, A. Everett, Jr,,

J. D. Whitcomb, and W. S, Johnson

September 1982

\section{HBMAM BดP}

OCT 191982

LANGLEY RESEARCH CENTER LIBRARY, NASA

HAMPTON, VIRGINIA 


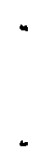




\title{
GEOMETRICALLY NONLINEAR ANALYSIS OF ADHESIVELY BONDED JOINTS
}

\author{
B. Dattaguru', R. A. Everett, Jr. ${ }^{2}$, J. D. Whitcomb, and W. S. Johnson \\ NASA Langley Research Center \\ Hampton, Virginia 23665
}

\begin{abstract}
A geometrically nonlinear finite-element analysis of cohesive failure in typical joints is presented. Cracked-lap-shear joints were chosen for analysis. Results obtained from linear and nonlinear analysis show that nonlinear effects, due to large rotations, significantly affect the calculated mode I, crack opening, and mode II, inplane shear, strain-energy-release rates. The ratio of the mode I to mode II strain-energy-release rates $\left(g_{I} / g_{I I}\right)$ was found to be strongly affected by the adhesive modulus and the adherend thickness. $\mathscr{y}_{\mathrm{I}} / \mathrm{f}_{\mathrm{I}}$ ratios between 0.2 and 0.8 can be obtained by varying adherend thickness and using either a single or double cracked-lap-shear specimen configuration. Debond growth rate data, together with the anaiysis, indicate that mode I strainenergy-release rate governs debond growth. Results from the present analysis agree well with experimentally measured joint opening displacements.
\end{abstract}

\footnotetext{
${ }^{1}$ National Research Council Resident Research Associate.

${ }^{2}$ Structures Laboratory, U.S. Army Research and Technology Laboratories (AVRADCOM), NASA Langley Research Center, Hampton, VA 23665.
} 


\section{INTRODUCTION}

Joining structural components with adhesives offers many advantages over conventional mechanical fasteners: lower structural weight, lower fabrication cost, and improved damage tolerance have been demonstrated [1-5]. Fokker Aerospace has successfully built adhesively bonded aircraft for more than 30 years [4]. Significant new surface preparations and adhesives have appeared in the past 10 years that have enhanced the strength and durability of bonded joints. Even with all of the advantages and encouraging experiences with adhesive bonding, manufacturers still hesitate to apply this technology to primary structural components, citing lack of confidence from poor understanding and concern for long term durability. A Fokker report [5] showed that many of the past failures of bonded structures involved poor design. Most often the poor design could be attributed to inadequate understanding of the adhesion failure mechanics.

There are three dominant modes of mechanical failure in bonded joints: 1) adherend failure (including delamination if one of the adherends is a laminated composite), 2) interfacial failure between adhesive and an adherend and 3) cohesive failure within the adhesive. The objective of the current study was to contribute to the understanding of the mechanics of cohesive failure.

When a joint fails at the bond from cyclic loading, this failure mode is often called cyclic debonding-progressive separation of the adherends by cyclic failure of the adhesive. Previous researchers $[6,7]$ have shown that the strain-energyrelease rate defined from fracture mechanics principles can be used to correlate the cyclic debonding data. They used the total strain-energy-release rate as calculated from strength-of-materials principles. These results and more recent data [8] indicate that when mixed-mode loading is involved (i.e., peel and shear loads), cyclic debonding data can be correlated by an appropriate mix of mode I and mode II components of strain-energy-release rates. In general, these components of strain-energy cannot be calculated using strength of materials methods. A more 
accurate analysis is needed so that the strain-energy-release components can be calculated from the local forces and displacements around the debond tip. This paper presents an analytical study of cohesive failure in adhesively bonded joints using a geometrically nonlinear two-dimensional finite element analysis. The analysis presented resolves the strain-energy-release rate at the debond tip into mode $I$ and mode II components.

Cracked-lap-shear (CLS) joints (Fig. la) were chosen for this study because they represent mixed-mode loading and large area bonds typical of many structural applications. They are also convenient specimens for laboratory tests on debond growth. The analytical study on these joints provides an insight into the geometric nonlinear effects. Furthermore, the analysis of these specimens illustrates the effect of adherend and adhesive material properties and joint dimensions on the mode I and mode II strain-energy-release rates. Data on debond growth in CLS specimens were analyzed to assess the relative influence of mode I and II strainenergy-release rates. The results of the present analysis are compared to those of other researchers.

NOMENCLATURE
A area, $\mathrm{m}^{2}$
a length of debond, $m$
b width of specimen, $m$
$C_{i j k l} \quad$ material stiffness coefficients, GPa
$E_{1}, E_{2}$. Young's modulus in $x_{1}$ and $x_{2}$ directions, GPa
$E_{1 \ell}, E_{2 \ell} \quad$ Young's modulus in $x_{1}, x_{2}$ directions for lap adherend, GPa
$E_{1 s}, E_{2 s}$ Young's modulus in $x_{1}, x_{2}$ directions for strap adherend, GPa
$E_{a} \quad$ Young's modulus of adhesive, GPa
- $\mathrm{G}_{12}$ shear modulus, GPa
$\mathrm{G}_{\mathrm{a}} \quad$ shear modulus of adhesive, $\mathrm{GPa}$ 


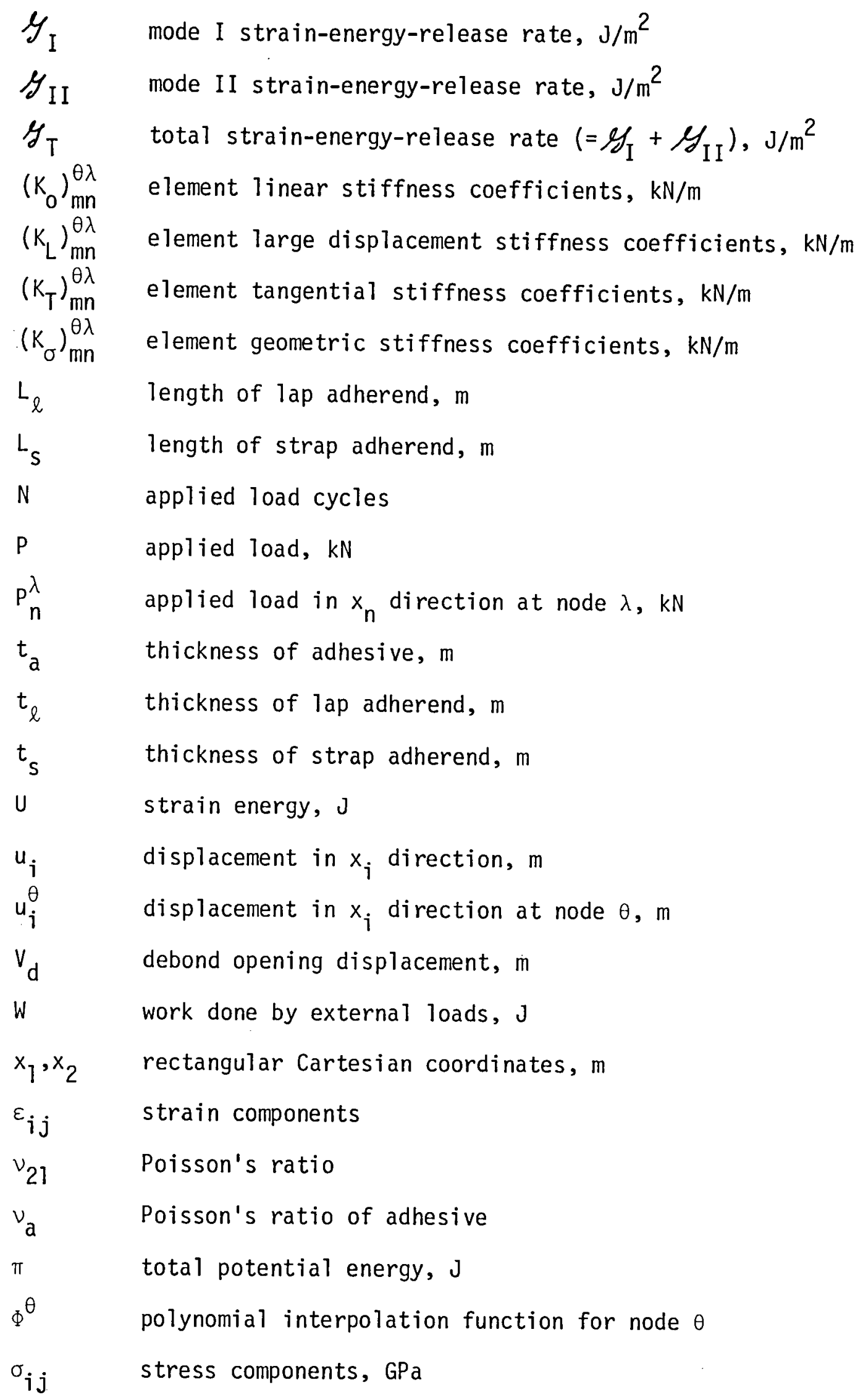


$\psi_{n}^{\lambda} \quad$ residual force in $x_{n}$ direction at node $\lambda, k N$

Indices:

$i, j, m, n, r$ Cartesian directions, range $=1,2$

$\lambda, \theta \quad$ node numbers connecting an element, range $=1,4$

\section{BASIC JOINT CONFIGURATION}

Figure la shows the basic cracked-lap-shear specimen configuration chosen for the present analysis. This base specimen consists of a $203 \mathrm{~mm}$ long lap adherend bonded over a $254 \mathrm{~mm}$ long strap adherend. The strap adherend was $3.2 \mathrm{~mm}$ thick 2024-T3 aluminum and the lap adherend was $1.6 \mathrm{~mm}$ thick unidirectional graphite/ epoxy. The adherends were bonded with a room temperature cure adhesive EA-934. The material properties of the adherends and adhesive were taken from the literature $[9,10]$ and are shown in table 1 . In the analytical results presented in this paper, one or more dimensions or properties were varied. Any variations from the base specimen are indicated wherever they occur.

TABLE 1.- MATERIAL PROPERTIES.

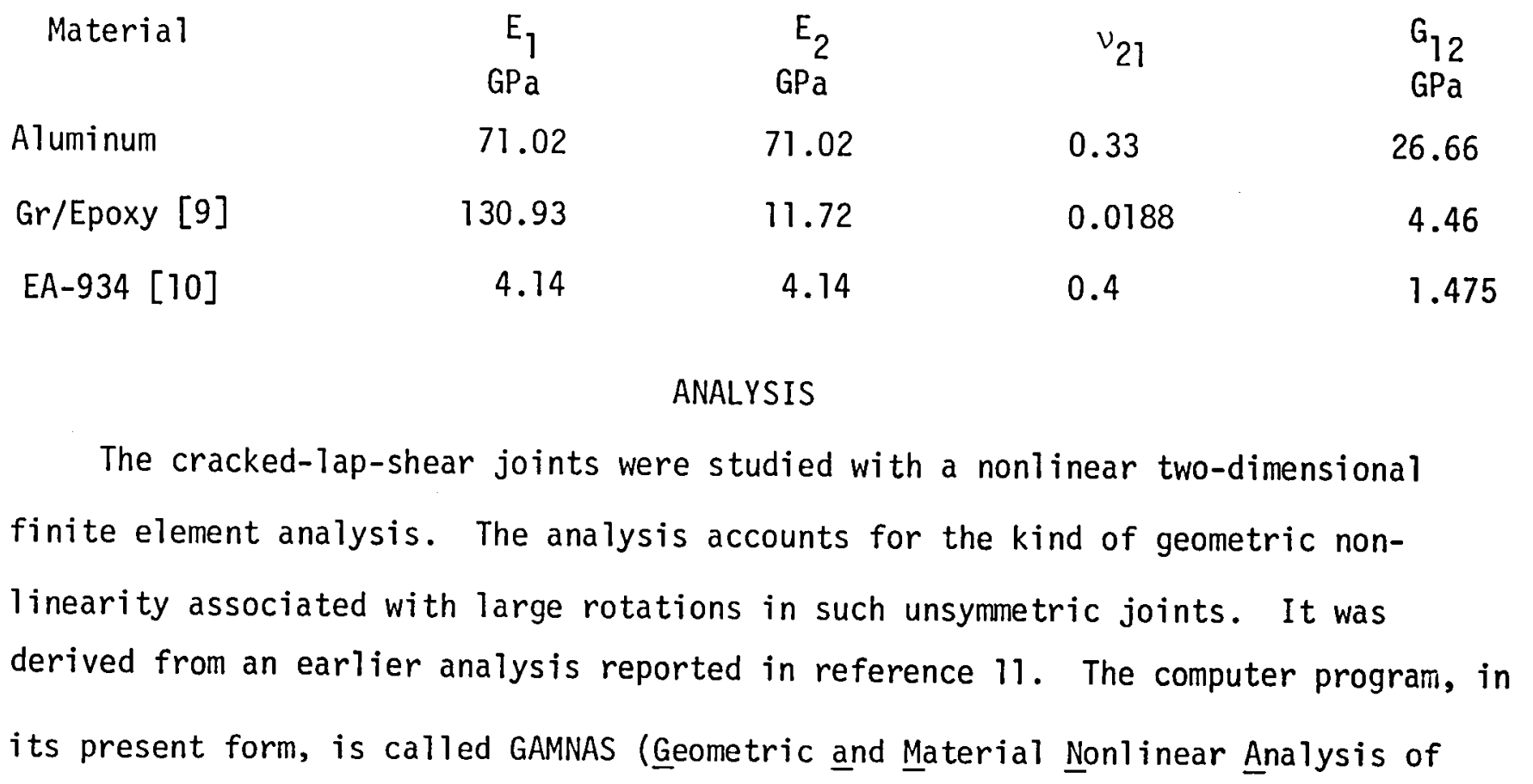


Structures). A two-dimensional idealization and the coordinate system used for the analysis are shown in fig. 1b. The theoretical basis for the analysis is described in the following paragraphs.

\section{Governing Equations}

In the following development of governing equations Cartesian tensor notation is used. The governing nonlinear equations for individual elements can be derived using the principle of minimum total potential energy. The total potential energy, $\pi$, is given by equation (1) [12].

$$
\Pi=U-W=\frac{b}{2} \int \sigma_{i j} \varepsilon_{i j} d A-W
$$

Geometric nonlinearity is included by using the nonlinear strain-displacement relation [13] in equation (1).

$$
\varepsilon_{i j}=\frac{l}{2}\left(\frac{\partial u_{i}}{\partial x_{j}}+\frac{\partial u_{j}}{\partial x_{i}}+\frac{\partial u_{r}}{\partial x_{i}} \frac{\partial u_{r}}{\partial x_{j}}\right)
$$

The displacements $u_{1}$ and $u_{2}$ within an element are approximated with interpolation functions, that is

$$
u_{i}=\Phi u_{i}^{\theta}
$$

Using equations (1), (2), and (3) to calculate and minimize $\Pi$ with respect to $u_{i}^{\theta}$ yields

$$
b \int \sigma_{i j} \frac{\partial \varepsilon_{i j}}{\partial u_{n}^{\lambda}} d A=P_{n}^{\lambda}
$$

Equations (4) are the set of governing nonlinear equations for the element. The equations for all elements are assembled to form a system of governing equations.

The assembled nonlinear governing equations are solved iteratively using a modified Newton-Raphson method [12]. To implement this method, the assembled 
tangential stiffness matrix is obtained by combining the individual element stiffness matrices. The element tangential stiffness matrix is obtained from equation (4) by partial differentiation as follows:

$$
\left(K_{T}\right)_{m n}^{0 \lambda}=b \frac{\partial}{\partial u_{m}^{0}}\left(\int_{\sigma_{i j}} \frac{\partial \varepsilon_{i j}}{\partial u_{n}^{\lambda}} d A\right)
$$

Performing the differentiation and simplifying results in

$$
\left(K_{T}\right)_{m n}^{0 \lambda}=\left(K_{0}\right)_{m n}^{0 \lambda}+\left(K_{L}\right)_{m n}^{0 \lambda}+\left(K_{0}\right)_{m n}^{0 \lambda}
$$

where

$$
\left(K_{0}\right)_{m n}^{0 \lambda}+\left(K_{L}\right)_{m n}^{0 \lambda}=b \int c_{i j k \ell} \frac{\partial \varepsilon_{k \ell}}{\partial u_{m}^{0}} \frac{\partial \varepsilon_{i j}}{\partial u_{n}^{\lambda}} d A
$$

and

$$
\left(K_{\sigma}\right)_{m n}^{\theta \lambda}=b \int s_{m n} \sigma_{i j} \frac{\partial \varphi^{\lambda}}{\partial x_{i}} \frac{\partial \Phi^{0}}{\partial x_{j}} d A
$$

$\left(K_{0}\right)_{m n}^{0 \lambda},\left(K_{L}\right)_{m n}^{0 \lambda}$, and $\left(K_{\sigma}\right)_{m n}^{\theta \lambda}$ are the linear, large displacement, and geometric stiffness matrices, of each element, 'respectively.

The elements used in the analysis were four-node, isoparametric quadrilaterals. To improve the performance of the elements in modeling bending deformation, a selective reduced numerical integration scheme $[11,14,15]$ was used to evaluate the element stiffness matrices. The procedure for calculating the linear stiffness matrix $\left(K_{0}\right)$ is described in references 14 and 15 . Application of reduced integration to nonlinear analysis is described in reference 11. 


\section{Calculation of Strain-Energy-Release Rates}

Strain-energy-release rates were calculated using a crack closure technique like that reported in reference 16 . The forces transmitted through the node at the crack tip and the relative displacements of the two nodes on the crack boundary closest to the crack tip were used to calculate the energy required to close the crack. Because the rotations are significant, the nodal forces were calculated using equation (4). The forces calculated with equation (4) and the displacements were defined relative to a fixed coordinate system. These quantities must be transformed to obtain the components normal and tangential to the rotated bondline. Figure 2 shows the original and the transformed coordinates. The mode I strainrelease-rate, $\mathscr{Y}_{I}$, was calculated from the force and displacement components normal to the rotated bondline. $y_{\text {II }}$ is due to in-plane shear mode of fracture and was obtained from the corresponding tangential components. The strain-energy-release rates $y_{I}$ and $y_{\text {II }}$ were obtained as (see fig. 2)

$$
\begin{aligned}
& y_{I}=\frac{1}{2} P_{\bar{x} 2} \frac{\left(\overline{u_{1}^{2}}-\overline{u_{1}^{3}}\right)}{b \Delta a} \\
& y_{I I}=\frac{1}{2} P_{\bar{x} 1} \frac{\left(\overline{u_{2}^{2}}-\overline{u_{2}^{3}}\right)}{b \Delta a}
\end{aligned}
$$

The total strain-energy-release rate, $\mathscr{Y}_{\mathrm{T}}$ is the sum of $\mathscr{Y}_{I}$ and $\mathscr{Y}_{\text {II }}$.

Finite Element Models

The typical finite element model shown in figure $1 \mathrm{~b}$ has 880 nodes and 792 elements. Other models had from 750 to 1100 nodes and 600 to 1000 elements and a convergence study showed that this level of refinement calculated the components of strain-energy-release rate within 3 percent of the values obtained with a much more refined mesh. Hence, this level of precision was deemed adequate. Boundary conditions are indicated in figure 1b. Under load, because of the eccentric load path, the ends of the CLS specimen try to rotate. But the CLS specimen is normally 
gripped such that the ends cannot rotate. So, to simulate grip loading, a multipoint constraint was imposed to prevent rotation of the loaded end of the model, i.e., all the $u_{1}$, displacements along the end are equal. For some of the configurations analyzed in this paper failure to properly model these grip conditions resulted in discrepancies up to 15 percent.

\section{RESULTS AND DISCUSSIONS}

In any structure, its response to applied load depends upon a number of geometric and material parameters. In this study, the cracked-lap-shear specimen was analyzed with the present nonlinear analysis, and the effect of several of these parameters on the mix of mode I and mode II components of strain-energyrelease rate were calculated. First, the need for a geometrically nonlinear analysis is shown. Then the effects of varying the adherend dimensions and the implications of the dimensions on the CLS specimens are discussed. The effects of adhesive properties variations demonstrate the need to model the adhesive in the analysis. In past studies on adhesively bonded joints, simplified strength-of-materials analyses have been used to study strain-energy-release-rate components in CLS specimens. Results from the present analysis are compared with those from strengthof-materials approach. Finally, the present analytical results are compared with experimental results.

The numerical results are presented for plane stress idealization of the joint. Plane strain idealization estimates lowered (up to 9 percent) values of mode I and mode II components of strain-energy-release rates, but the trends of results were the same as those for a plane stress idealization.

\section{Analytical Results}

Previously, researchers [17] showed that a geometrically nonlinear analysis was often needed when analyzing adhesively bonded structures. They showed that the stress distributions may differ significantly between a linear and nonlinear 
analysis. In the current study of the CLS specimen the difference between the strain-energy-release rate components were calculated using geometrically nonlinear and linear analyses. The results differed and are shown in fig. 3 for a debond length of $50.8 \mathrm{~mm}$. In this figure, $\mathscr{Y}_{I}$ is the strain-energy-release rate due to the opening mode of fracture, $\mathscr{H}_{\text {II }}$ is the strain-energy-release rate due to the in-plane shear mode of fracture. The linear and nonlinear values of $\mathscr{y}_{I}$ and $y_{I I}$, differ noticeably with the differences widening as the load increases, as would be expected. The data indicate the desirability of a geometrically nonlinear analysis of CLS specimens.

Analysis of the durability of bonded structures depends on the correlation of debond growth with the components of strain-energy-release rate. The basic CLS specimen configuration previously described was studied using the present nonlinear analysis. Figure 4 shows the mixed mode nature of the CLS specimen; the value of $\mathscr{Y}_{I}$ is approximately 50 percent of $\mathscr{Y}_{\text {II }}$. For this particular configuration $\mathscr{Y}_{I}$ and $\mathscr{Y}_{\text {II }}$ are essentially constant over most of the lap length; this simplifies the correlation of strain-energy-release rates with debond growth data.

In general, the strain-energy-release rates are not constant with debond length for specimens of all configurations. The adherend thicknesses relative to lap-length become important parameters in determining the variation of $\mathscr{H}_{I}$ to $\mathscr{H}_{I}$ ratio along the lap length. Figure 5 shows how $\mathscr{H}_{I} / \mathscr{H}_{I I}$ varies with debond length at two different values of lap adherend thickness. One of the cases, $t_{\ell}=1.6 \mathrm{~mm}$, corresponds to the base configuration as shown in fig. 4. The variation of $y_{I} / y_{I I}$ with debond length is greatest for the specimen with thicker adherends.

A further analysis was carried out to understand whether the range of the $y_{I} / \mathscr{Y}_{\text {II }}$ ratio could be extended by changing the thickness of the lap adhered relative to the strap adherend. The results of this analysis, for a CLS specimen 
with $50.8 \mathrm{~mm}$ debond, is shown in figure 6 . Also shown is the trend for a configuration called a double-CLS specimen (DCLS). The DCLS specimen, which is symmetric as shown in figure 6 , consists of an aluminum strap with two graphite/epoxy lap adherends bonded to each side of the aluminum. Results show that a wide range of $\mathscr{Y}_{\text {I }}$ to $\mathscr{Y}_{\text {II }}$ ratios can be obtained by choosing the proper combination of adherend thicknesses and specimen configuration, i.e., CLS or DCLS.

If each side of the DCLS debonds at the same rate, the specimen as a whole does not rotate. For this case the DCLS specimen has a higher $\mathscr{H}_{I}$ to $\mathscr{H}_{\text {II }}$ ratio than the CLS specimen (fig. 6). But previous tests [7] showed that symmetric debond growth rarely occurred. When the debond growth is unsymmetric, the ratio of $\mathscr{H}_{I}$ to $\mathscr{Y}_{\text {II }}$ must be calculated for the unsymmetric configuration, and would not be as shown in fig. 6 .

In any structural analysis the validity of the results depends upon the accuracy of the material properties used. In the present analysis of the CLS specimen the influence of the shear modulus and Poisson's ratio of the adhesive on the strain-energy-release rate were studied. The results are shown in figure 7. For the configuration analyzed, the curves show that $\mathscr{I}_{I}$ and $\mathscr{Y}_{\text {II }}$ are noticeably affected by the adhesive shear modulus while Poisson's ratio does not appreciably affect either $\mathscr{Y}_{\text {I }}$ or $\mathscr{Y}_{\text {II }}$. In fact, $\mathscr{S}_{\text {I }}$ and $\mathscr{Y}_{\text {II }}$ are quite sensitive to changes in the adhesive shear modulus below $2 \mathrm{GPa}$. This is significant because most current technology adhesives have shear moduli less than $2 \mathrm{GPa}$. Also, these results show the need to have accurate adhesive shear modulus data when calculating the strainenergy-release rates.

Researchers $[17,18]$ have shown that the through-the-thickness variation of the adhesive stresses is important. So, the influence of debond location on strainenergy-release-rates was studied. All the preceding analytical results in the report have been for a middle-of-bond cohesive failure. Calculations of strainenergy-release rates for a middle-of-bond cohesive failure and a failure mode that 
is near the adhesive/aluminum interface are shown in figure 8. These results show that the calculated values of $g_{I}$ are greater for a failure that is near the interface, while those for $y_{\text {II }}$ are greater for a center of bond failure. Because of the expense of performing finite-element analysis, previous studies have often sought to simplify the analysis by considering a strengthof-materials approach $[7,8]$. Results derived from a strength-of-materials analysis for a CLS joint [8] are compared with finite-element results in figure 9. The strength of materials analys is was developed for metal adherends and did not account for the presence of adhesive. Therefore, comparative results were also obtained on a modified finite-element model for an aluminumaluminum CLS joint which does not contain the adhesive. Figure 9 presents the $g_{I} / y_{I I}$ ratio versus the lap adherend thickness obtained with the present nonlinear and strength-of-materials analyses. This comparison indicates that the two analyses agree only when the adherend thicknesses are nearly equal $\left(t_{\ell}=t_{s}\right)$. Furthermore, considerable disagreement exists between the trends of the two analyses. These results suggest the strength of materials analysis is not appropriate except for equal thickness adherends.

\section{Comparison of Analytical and Experimental Results}

Two examples of CLS joint tests are presented to show how well the present nonlinear analysis predicts test results and how it helps data interpretation.

In the laboratory, only displacement and load can be measured directly. For the CLS specimen configuration (debond length $=50.8 \mathrm{~m}$ ) used in the study, the debond opening displacement, $V_{d}$, was measured at the free end of the graphite/ epoxy laminate and is shown in figure 10. Excellent agreement was obtained between the present nonlinear analysis and the test data. The linear analysis overestimated the debond opening displacement, especially at the higher loads.

Everett [19] hypothesized that $f_{I}$ is the principal mechanism in causing debond growth in a CLS specimen. Several tests were designed in reference 19 to show the 
role of $\mathscr{H}_{I}$ during cyclic debond growth. For these tests it was hypothesized that if a sufficient clamping force was applied to a bonded joint ahead of the advancing debond, this clamping force would oppose the peel stresses that drive the debond and stop the debond at the clamp.

A series of constant amplitude fatigue tests were run on the basic CLS specimen configuration under a maximum cyclic load per unit width of $482 \mathrm{kN} / \mathrm{m}$. When a clamping force per unit width of $9.6 \mathrm{kN} / \mathrm{m}$ or greater was applied to the specimen, the debond growth essentially stopped. The debond growth rate, da/dN, obtained from reference 19, is presented in figure 11. For the identical CLS specimen configuration and loading, the strain-energy-release rates were calculated. These results are shown in figure 11. Both $\mathscr{y}_{I}$ and $\mathscr{y}_{\text {II }}$ were nearly constant until the debond approached the clamp point (point $D$ in figure 11). The peel stress component $\mathscr{S}_{I}$ decreased to nearly zero close to this point. In contrast, $\mathcal{H}_{\text {II }}$ increased near point $D$. These trends support the hypothesis that the peel stresses are likely to be the principal cause of cyclic debond growth.

\section{CONCLUSIONS}

A geometrically nonlinear finite element analysis was used to study the mechanics of cohesive failure in adhesively bonded structures. Cracked-lap-shear (CLS) specimens that experience the mixed-mode loading typical of structures were analyzed and tested. The results led to the following conclusions:

1. Nonlinear effects due to large rotations are pronounced in CLS specimens and they significantly affect the calculated mode I and mode II strain-energyrelease rates, $\mathscr{S}_{I}$ and $\mathscr{H}_{I I}$.

2. By varying adherend thickness and specimen configuration, the ratio $\mathscr{S}_{\mathrm{I}} / \mathscr{S}_{\mathrm{II}}$ can be varied widely. The length of the joint and the lap length significantly affect $\mathscr{Y}_{I}, \mathscr{Y}_{I I}$ as the joint debonds.

3. Adhesive properties significantly affect the calculated values of $y_{I}$ and 
$y_{\text {II }}$. This indicates that the adhesive must be included in the analysis.

4. The test results on debond growth imply that the mode I strain-energyrelease rate is the main driver of cyclic debonding in the CLS specimen.

\section{REFERENCES}

1. Potter, D. L., et al.: Primary Adhesively Bonded Structure Technology (PABST), Design Handbook for Adhesive Bonding. AFFDL-TR-79-3129, November 1979.

2. Maris, J. L.; and Kuhn, G. E.: Advanced Technology Wing Structure. AFWALTR-80-3031, May 1980.

3. Reinhart, T. J.: Use of Structural Adhesives by the U.S. Air Force. Adhesives Age, August 1981.

4. Irving, R. R.: A Tale of Adhesively Bonded Aircraft. Iron Age, May 1981.

5. Schlickelmann, R. J.: Past, Present, and Future of Structural Adhesive Bonding in Aerospace Application. Trans. JSCM, vol. 5, no. 1-2, December 1979.

6. Mostovoy, S.; and Ripling, E. J.: Fracturing Characteristics of Adhesive Joints. Final Report of Naval Air Systems Command, Contract No. N00019-720250, December 1972.

7. Roderick, G. L.; Everett, R. A., Jr.; and Crews, J. H., Jr.: Cyclic Debonding of Unidirectional Composite Bonded to Aluminum Sheet for Constant Amplitude Loading. NASA TN D-8126, 1976.

8. Brussat, T. R.; Chiu, S. T.; and Mostovoy, S.: Fracture Mechanics for Structural Adhesive Bonds--Final Report. AFML-TR-77-163, 1977.

9. Advanced Composites Design Guide. Air Force Flight Dynamics Laboratory, 1971.

10. Roderick, G. L.: Crack Propagation in Aluminum Sheets Reinforced with BoronEpoxy. Ph.D. Dissertation, 01d Dominion University, May 1978.

11. Whitcomb, J. D.: Finite Element Analysis of Instability-Related Delamination Growth. NASA TM-81964, 1981. 
12. Zienkiewicz, 0. C.: The Finite Element Method in Engineering Science. Second Ed., McGraw-Hi1l, New York, 1971.

13. Novozhilov, V. V. (J. K. Lusher, transi.): Theory of Elasticity. Pergamon Press, New York, 1961.

14. Pawsey, S. F.; and Clough, R. W.: Improved Numerical Integration of Thick Shell Finite Elements. Int. J. for Numerical Methods in Eng., vol. 3, 1971, pp. 575-586.

15. Zienkiewicz, 0. C.; Taylor, R. L.; and Too, J. M.: Reduced Integration Technique in General Analysis of Plates and Shells. Int. J. for Numerical Methods in Eng., vol. 3, 1971, pp. 275-290.

16. Rybicki, E. F.; and Kanninen, M. F.: A Finite Element Calculation of Stress Intensity Factors by a Modified Crack Closure Integral. Eng. Fract. Mech., vol. 9, 1977, pp. 931-938.

17. Cooper, P. A.; and Sawyer, J. W.: A Critical Examination of Stresses in an Elastic Single Lap Joint. NASA TP-1507, 1979.

18. Romanko, J.; and Knauss, W. G.: Fatigue Behavior of Adhesively Bonded Joints. AFWAL-TR-80-4037, vol. I, April 1980.

19. Everett, R. A., Jr.: The Significance of Peel Stresses in Cyclic Debonding. M.S. Thesis, 0ld Dominion University, 1980. 


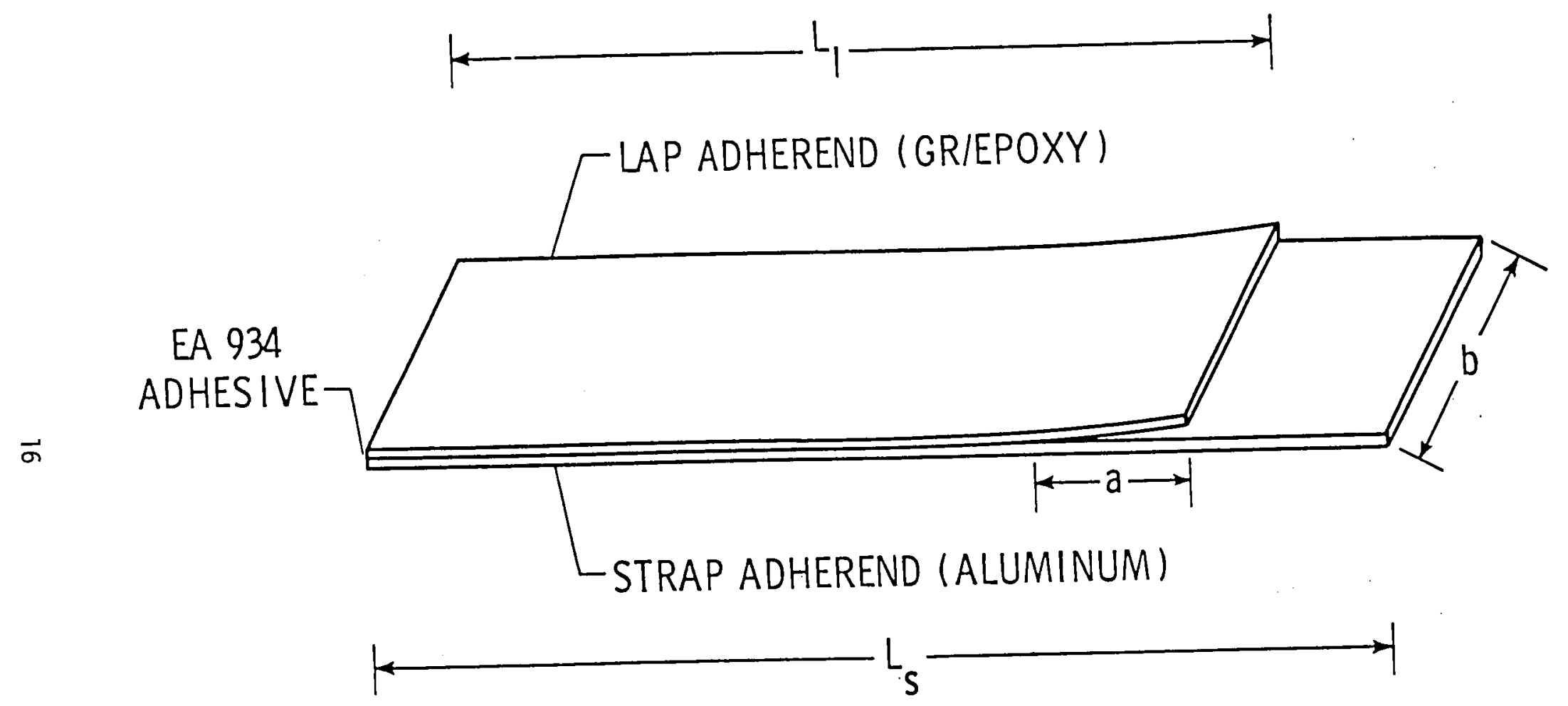

(a) Basic CLS specimen.

Fig. 1 Basic configuration and finite-element model. 


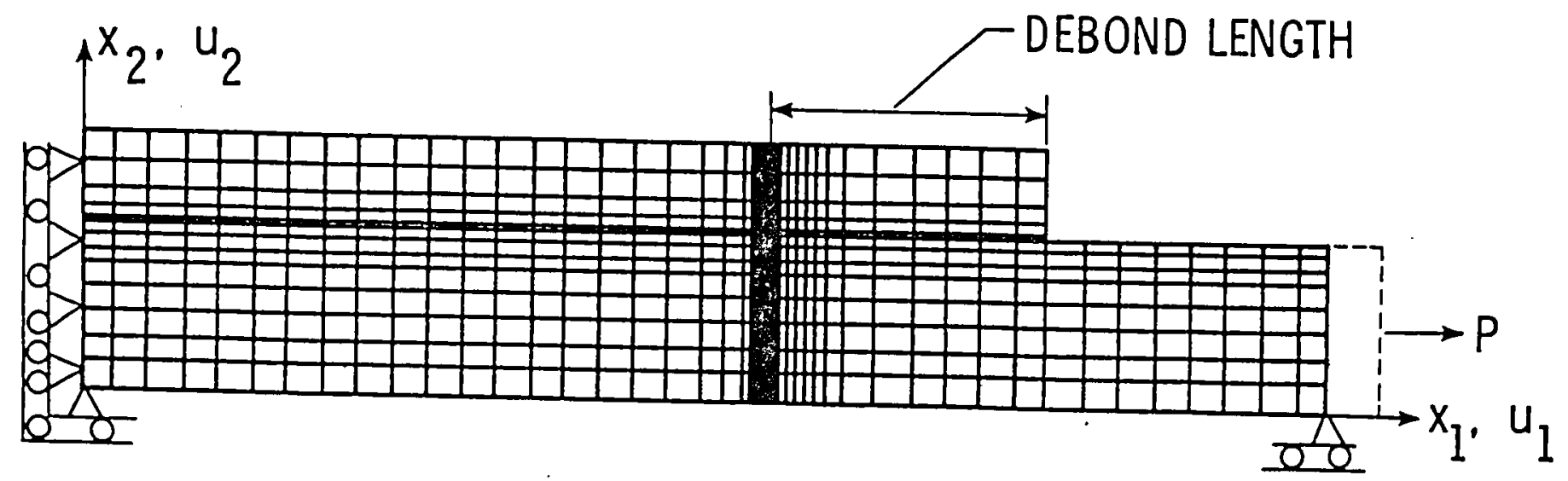

FINITE ELEMENT MESH $\left(x_{2}\right.$ COORDINATES ARE 10 TIMES MAGNIFIED )

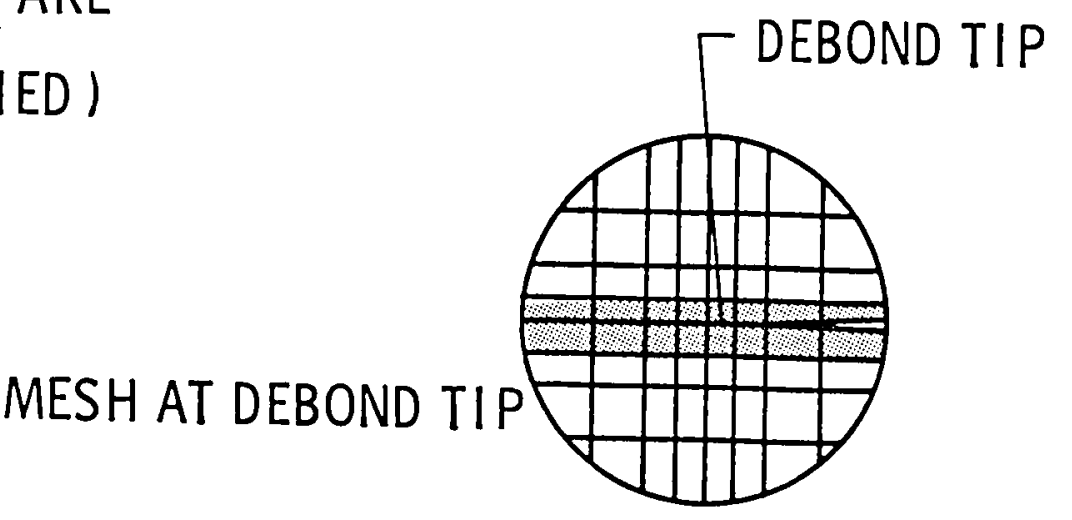

(b) Finite-element mesh ( $x_{2}$ coordinates are 10 times magnified),

Fig, 1 Basic configuration and finite-element model. 


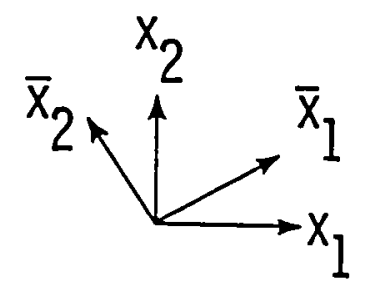

$$
\begin{aligned}
& \mathscr{Y}_{I}=1 / 2 \mathrm{P}_{\bar{x}_{2}} \frac{\left(\overline{U_{2}^{2}}-\overline{U_{2}^{3}}\right)}{\Delta a} \\
& y_{I I}=1 / 2 P_{\bar{x}_{1}} \frac{\left(\overline{u_{1}^{2}}-\overline{U_{1}^{3}}\right)}{\Delta a}
\end{aligned}
$$

Fig. 2 Transformed coordinate system for $\mathscr{Y}$-calculation. 


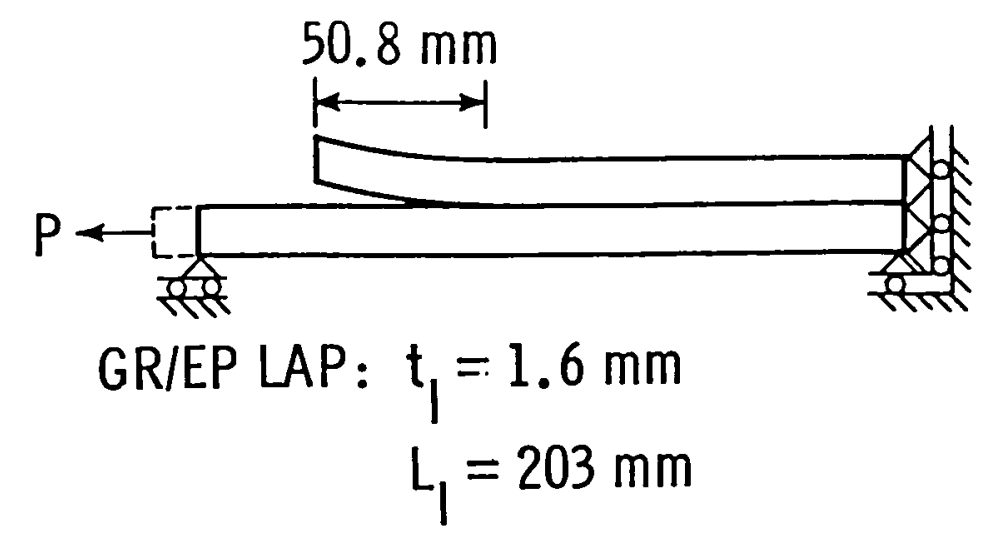

ALUMINUM STRAP:

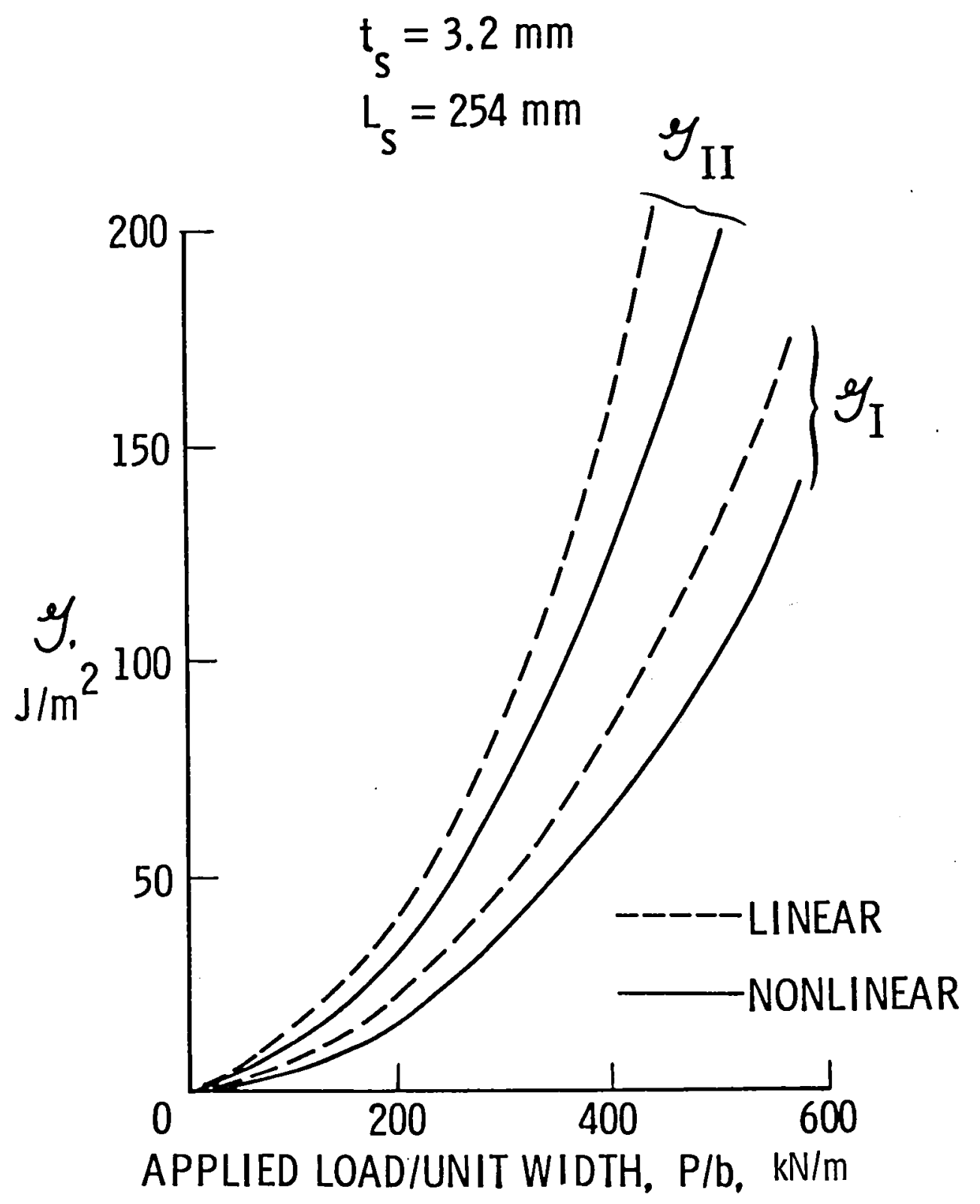

Fig. 3 Comparison of $\mathscr{Y}_{I}$ and $\mathscr{Y}_{\text {II }}$ calculated from linear and nonlinear analysis. 

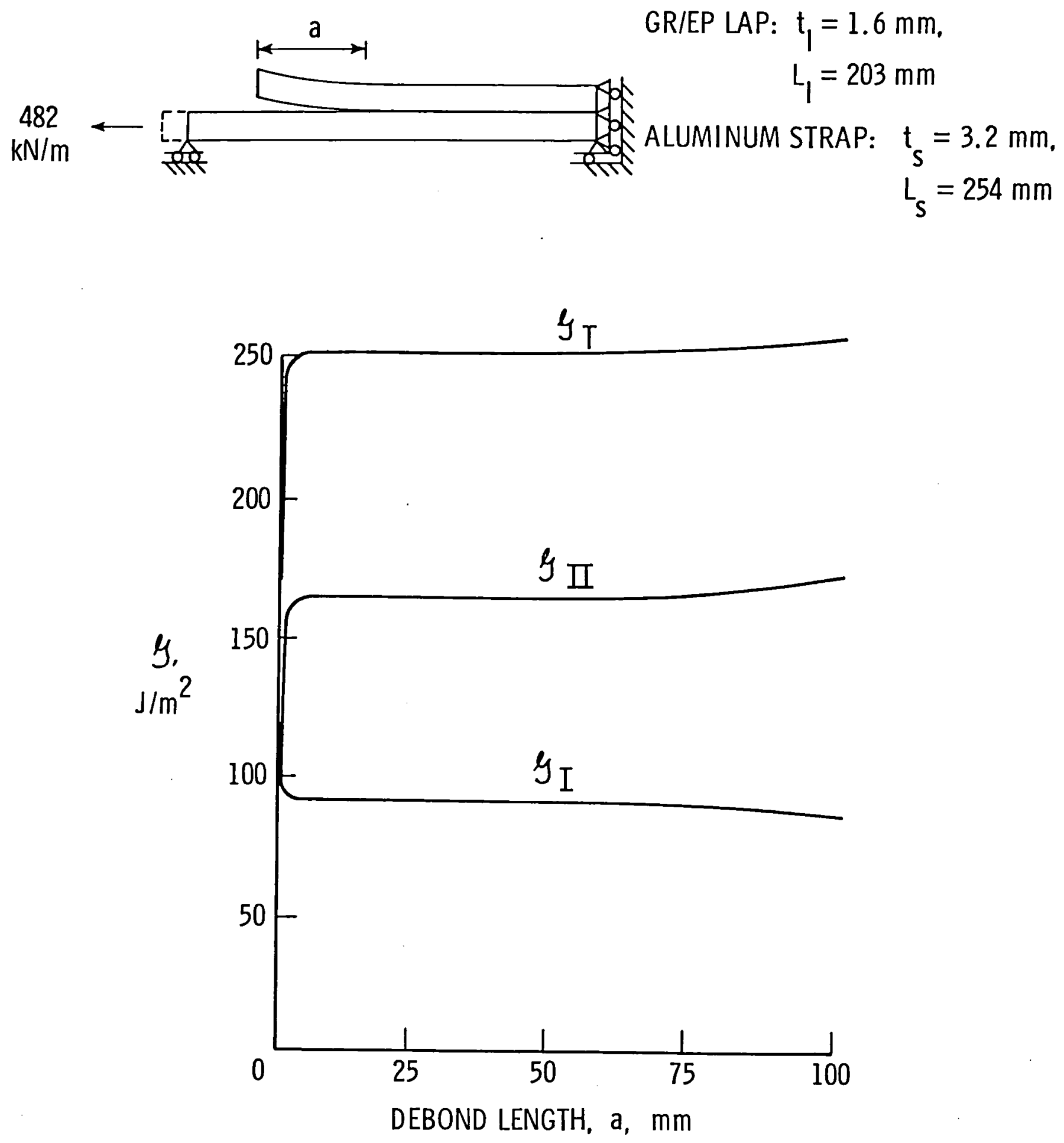

Fig. 4 Variation of strain-energy-release rates with debond length. 


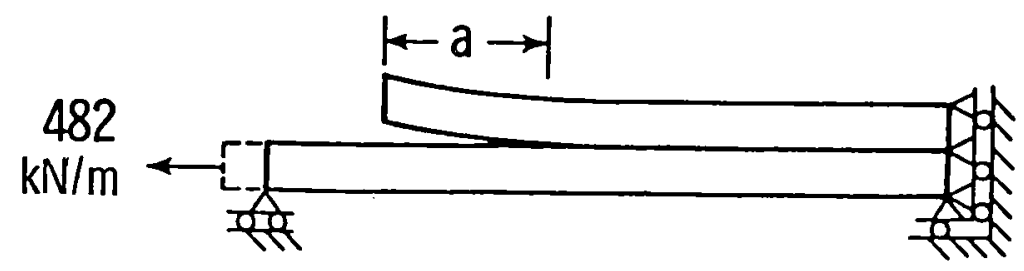

GR/EP LAP: $L_{1}=203 \mathrm{~mm}$

ALUMINUM STRAP:

$$
\begin{aligned}
& t_{\mathrm{s}}=3.2 \mathrm{~mm} \\
& \mathrm{~L}_{\mathrm{s}}=254 \mathrm{~mm}
\end{aligned}
$$

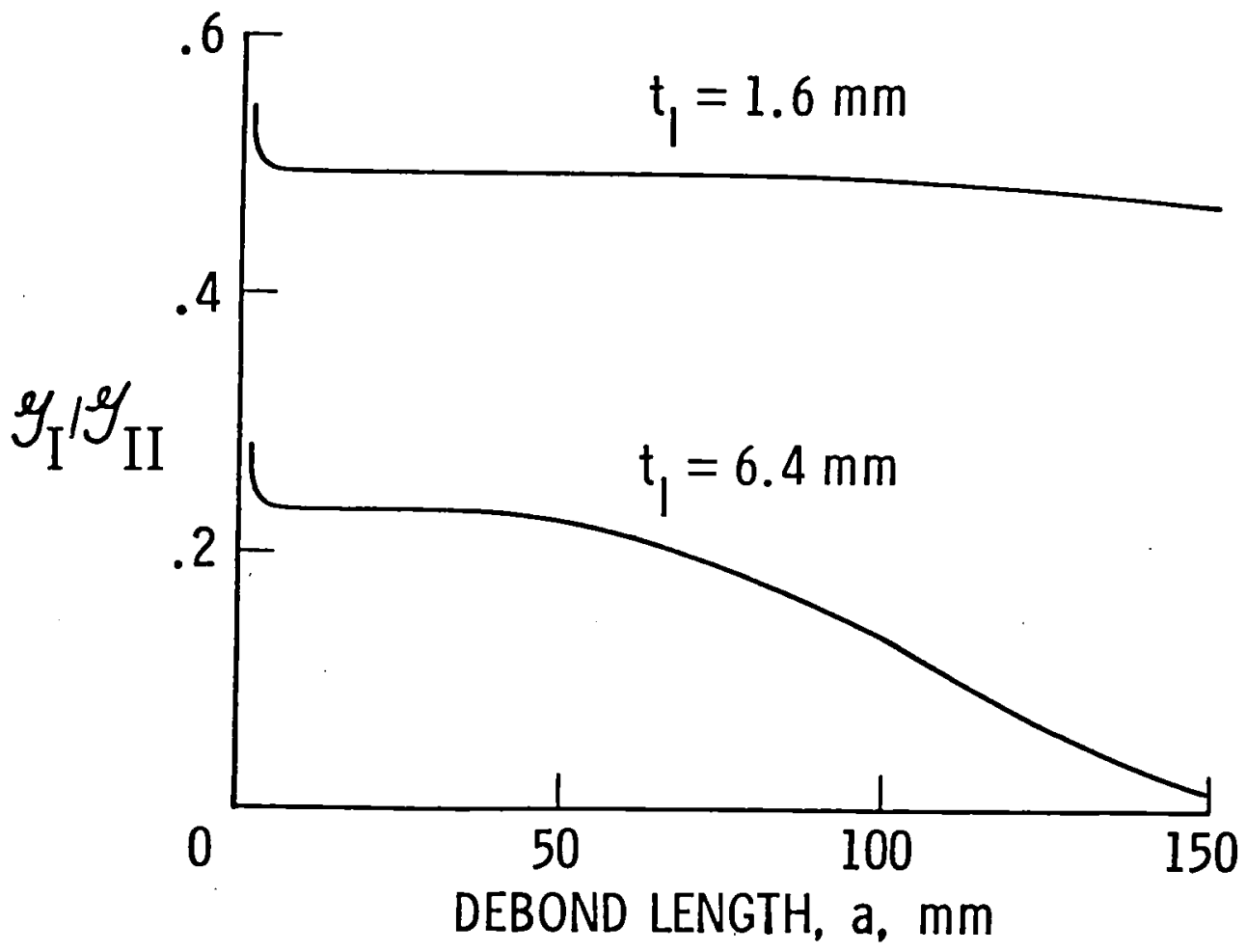

Fig. 5 Effect of lap adherend thickness on variation of $\mathscr{g}_{I} / \mathscr{y}_{\text {II }}$ ratio with debond length. 
GR/EP LAP: $L_{1}=203 \mathrm{~min}$

ALUMINUM STRAP: $\mathrm{L}_{\mathrm{S}}=254 \mathrm{~mm}$
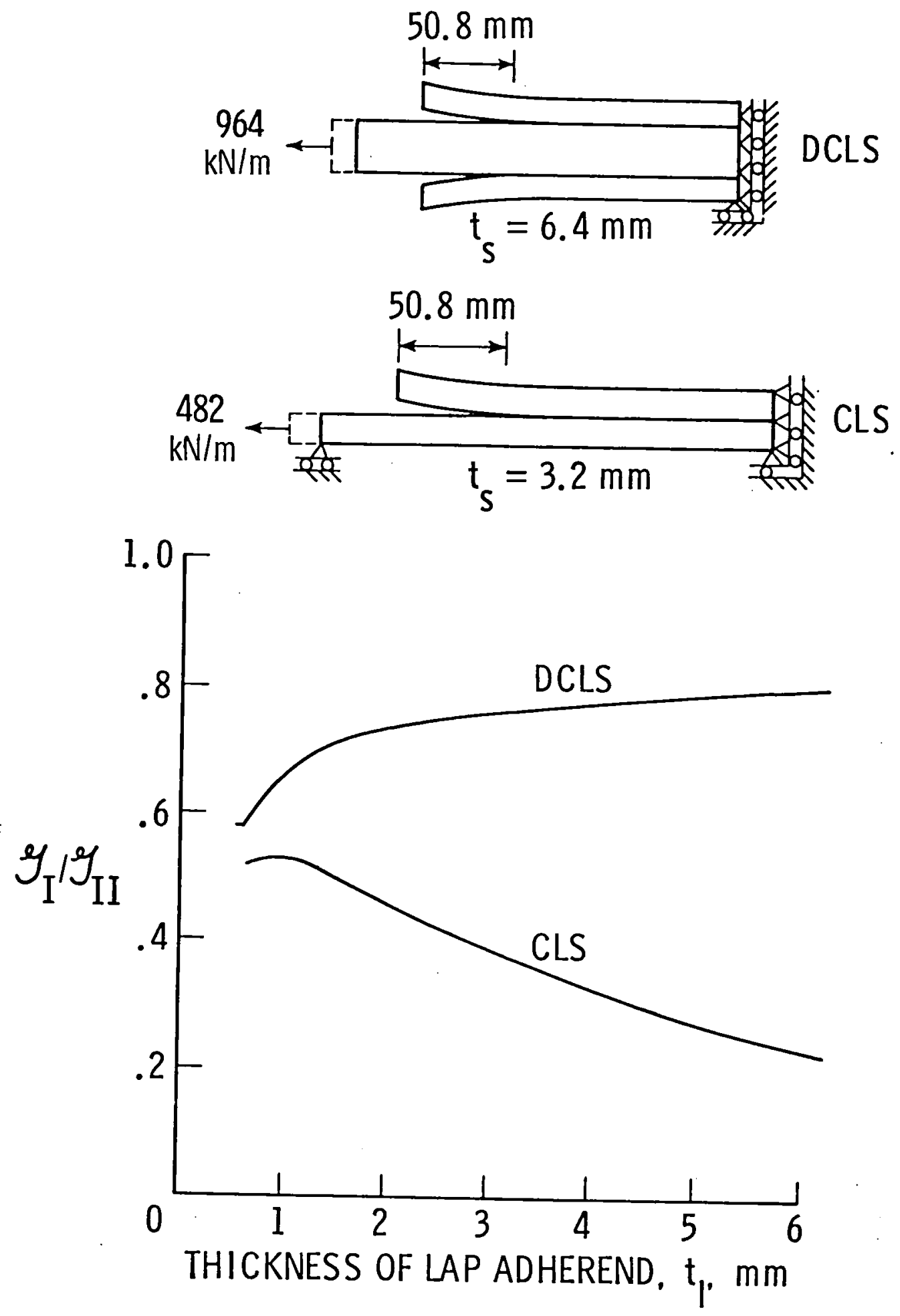

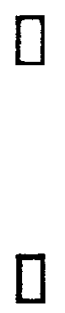

$\square$

$\square$

$\square$

Fig. 6 Effect of lap adherend thickness on $\mathscr{Y}_{I} / \mathscr{Y}_{I I}$. 
$50.8 \mathrm{~mm}$

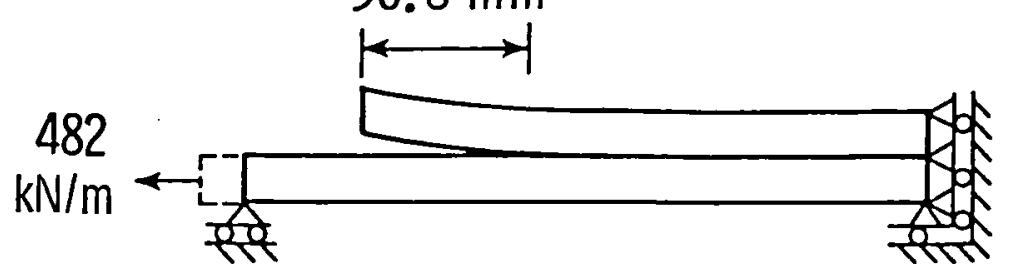

GR/EP LAP: $t_{1}=1.6 \mathrm{~mm}$

$\mathrm{L}_{\mathrm{I}}=203 \mathrm{~mm}$

ALUMINUM STRAP:

$\mathrm{t}_{\mathrm{s}}=3.2 \mathrm{~mm}$
$\mathrm{~L}_{\mathrm{s}}=254 \mathrm{~mm}$

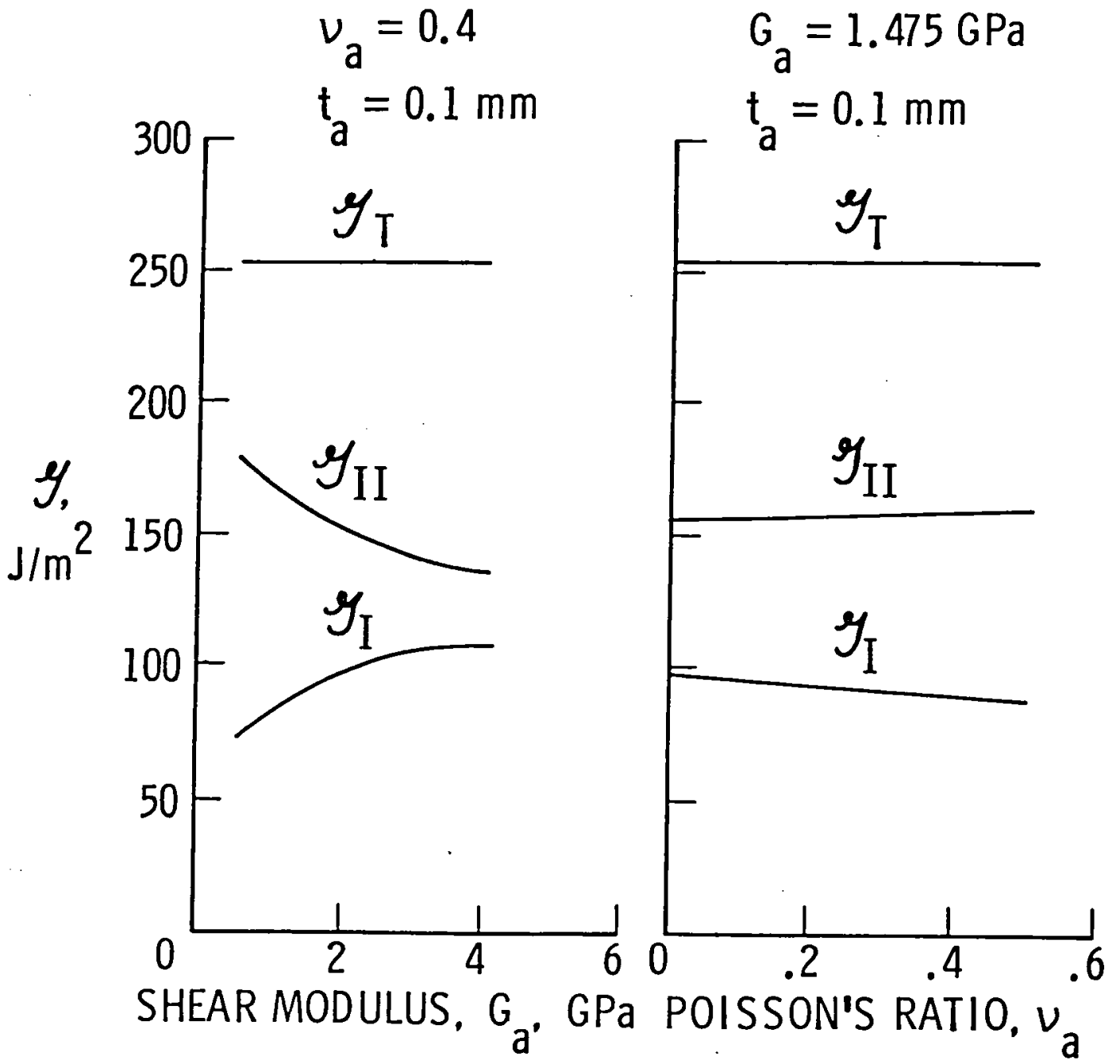

Fig, 7 Effect of adhesive material properties on strain-energy-release rates. 
GR/EP LAP: $\mathrm{t}_{1}=1.6 \mathrm{~mm}$.
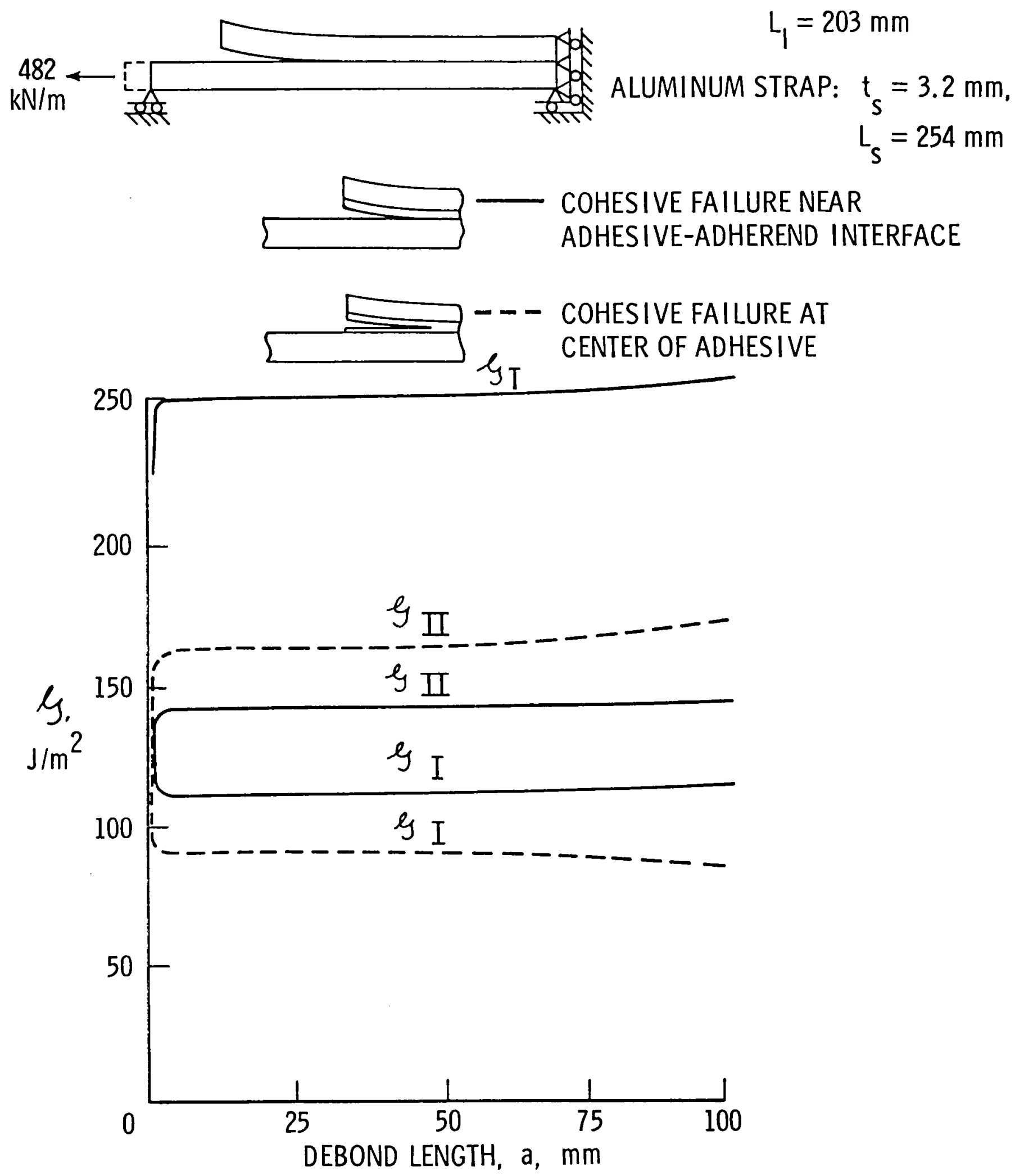

Fig. 8 Comparison of $y$ for fallure at center of adhesive and failure near adhesive-adherend interface. 


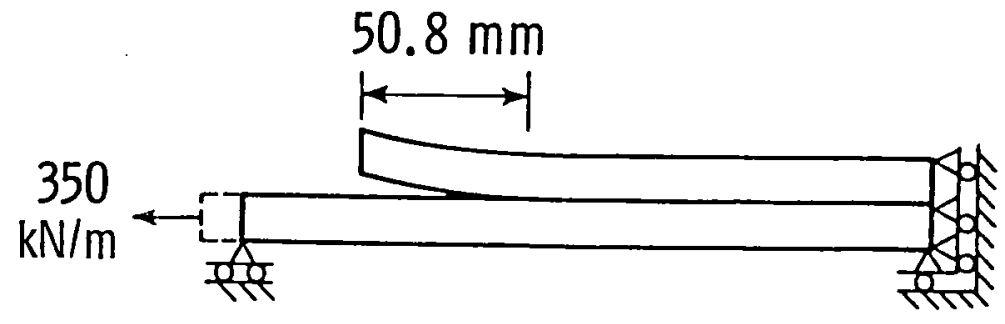

ALUMINUM LAP: $L_{1}=203 \mathrm{~mm}$ ALUMINUM STRAP:

$$
\begin{aligned}
& t_{s}=3.2 \mathrm{~mm} \\
& L_{s}=254 \mathrm{~mm}
\end{aligned}
$$

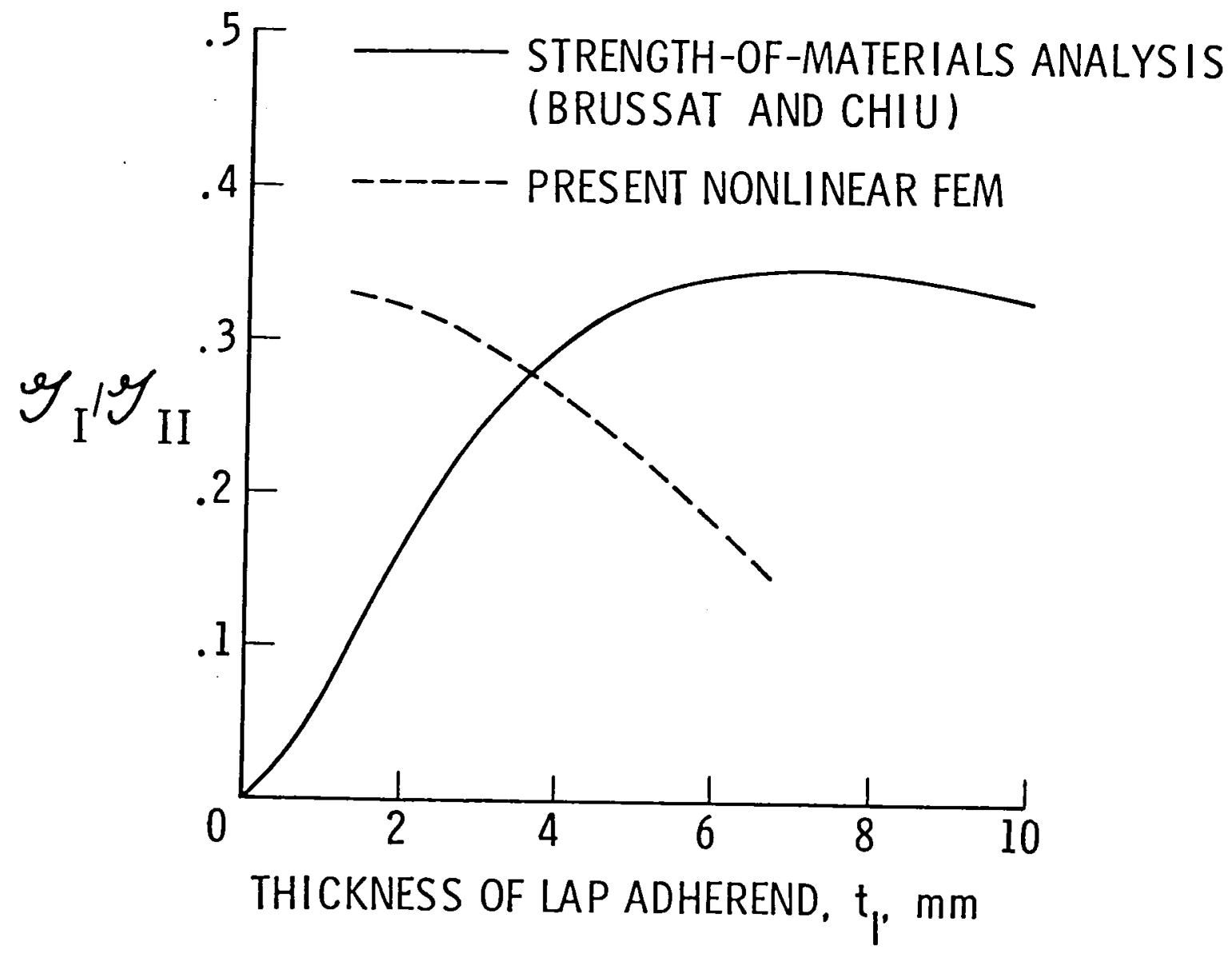

Fig, 9 Comparison of results from strength-of-materials and present nonl inear analyses. 

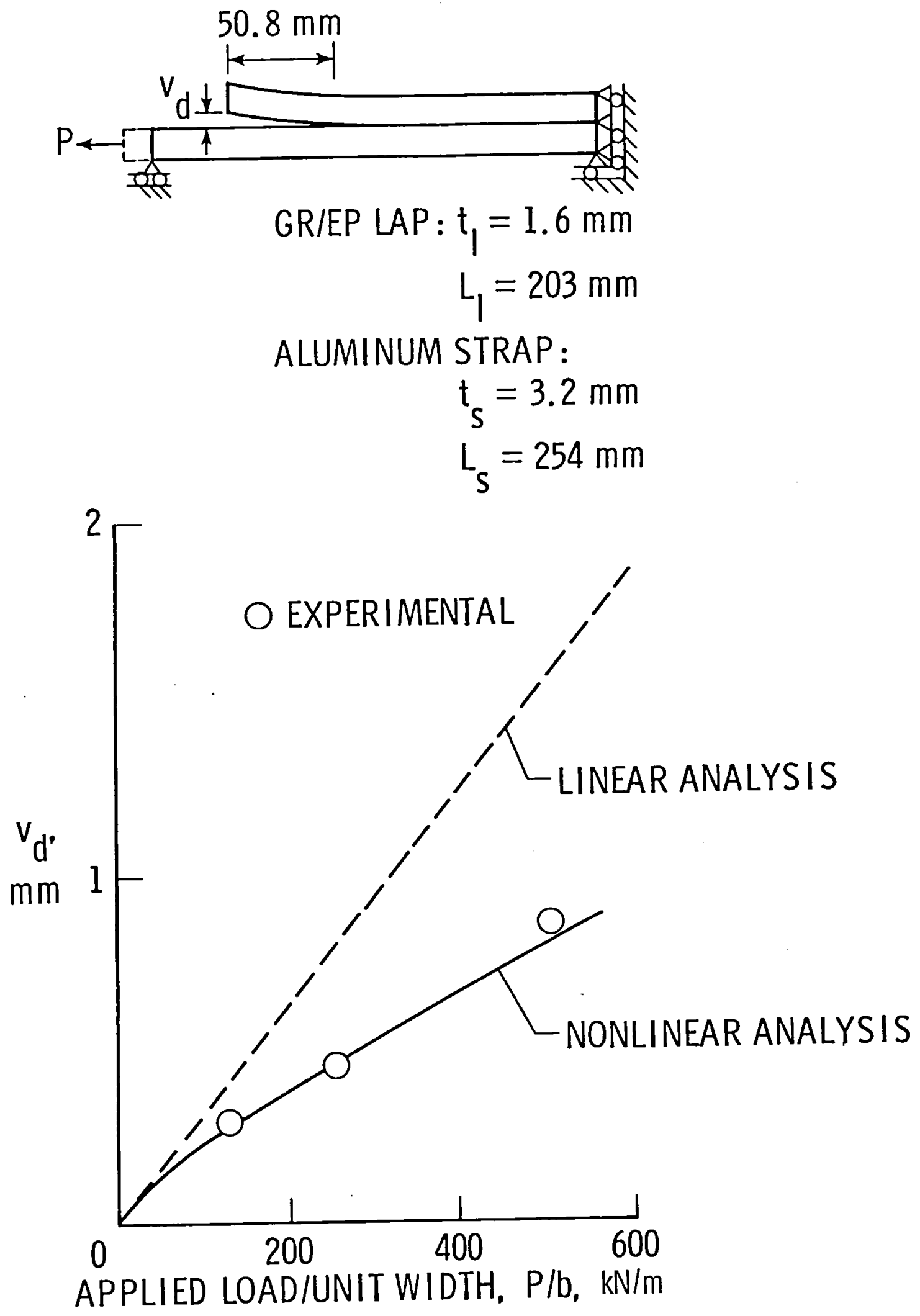

Fig, 10 Comparison of analytical results with experimental measurements of debond opening displacement, $v_{d}$. 


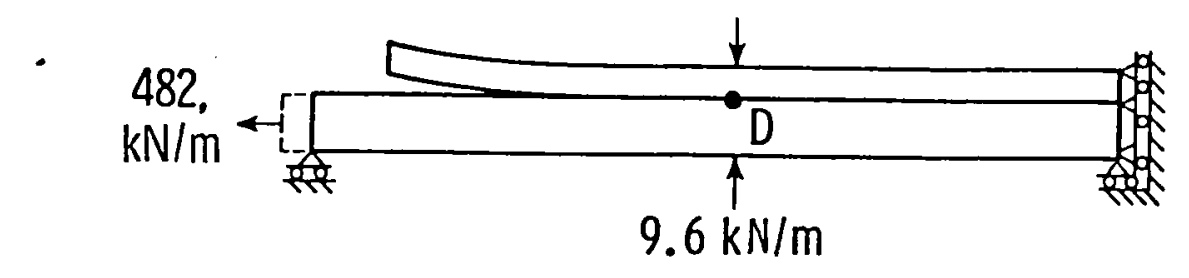

GR/EP LAP : $t_{1}=1.6 \mathrm{~mm}$

$L_{1}=203 \mathrm{~mm}$

ALUMINUM STRAP :

$$
\begin{aligned}
& t_{s}=3.2 \mathrm{~mm} \\
& L_{s}=254 \mathrm{~mm}
\end{aligned}
$$
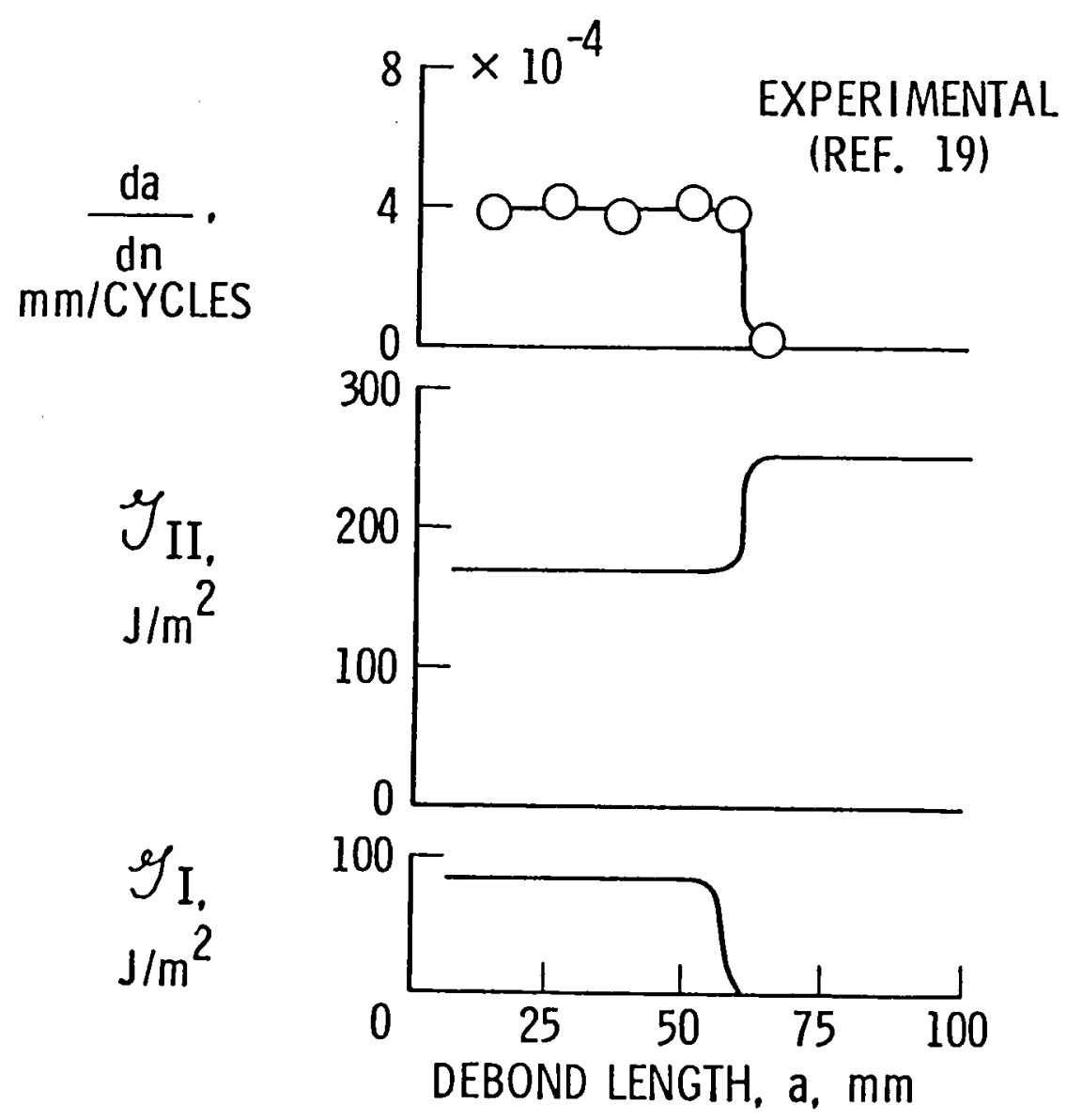

Fig. 11 Comparison of debond growth results with strain-energy-release rate components. 


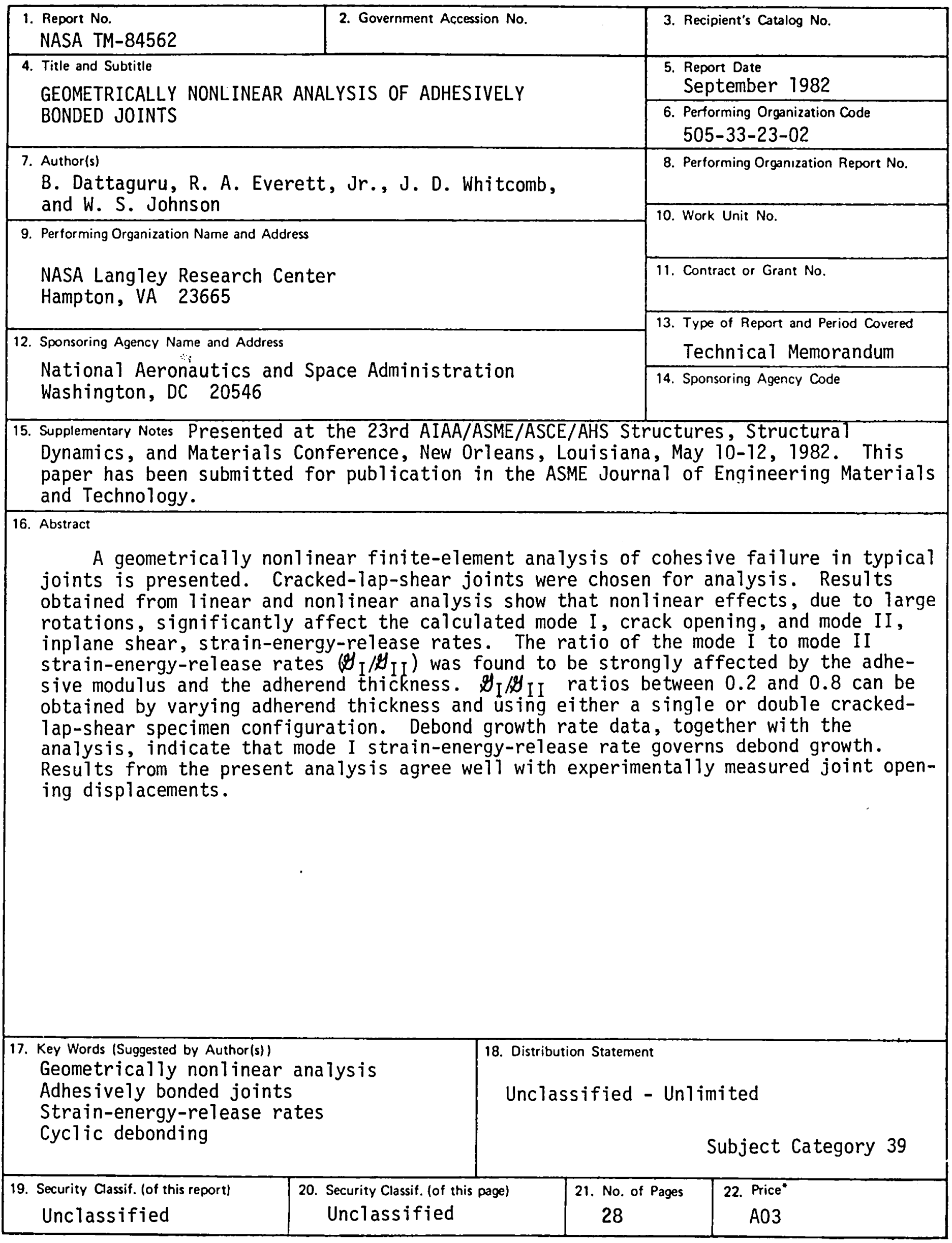

* For sale by the National Technical Information Service, Springfield, Virginia 22161 

